\title{
BIM-ENERGY SIMULATION APPROACH FOR DETECTING BUILDING SPACES WITH FAULTS AND PROBLEMATIC BEHAVIOR
}

SUBMITTED: May 2019

REVISED: May 2020

PUBLISHED: June 2020

EDITOR: Robert Amor

DOI: $10.36680 /$ j.itcon. 2020.020

Firas Shalabi, PhD,

Wiss, Janney, Elstner Associates, Inc.;

Rshalabi@wje.com

Yelda Turkan, PhD,

Oregon State University;

yelda.turkan@oregonstate.edu; https://cce.oregonstate.edu/turkan

SUMMARY: Heating and cooling consumes most of the energy in buildings. Faults and problems in HVAC systems waste up to $20 \%$ of heating and cooling energy. Identifying spaces with HVAC problems within a facility remains a major challenge for facility managers. This study aims to detect spaces with potential problems that causes energy overconsumption, human discomfort, or HVAC work overload. To achieve that, a Building Information Model (BIM)-based framework that combines the output data of building energy simulations, Building Energy Management Systems (BEMS), and Computerized Maintenance Management Systems (CMMS) is proposed. The framework enables BIM components to utilize data collected by the other systems to determine the intended energy performance and compare it with actual energy performance, as well as to provide access to maintenance history and BEMS alarms occurred in the building at element level. The framework was tested using data collected from an educational building over one-month period when the building was unoccupied to prevent users from manipulating the results. Experimental results show that the framework enabled identification of building spaces with abnormal or malfunctioning behavior that was not detected by the BEMS. This study supplements the body of knowledge in facilities energy management by providing a BIM-based framework that utilizes output data of energy simulation, BEMS and CMMS to locate and detect building spaces with potential problems that need maintenance. Furthermore, it enables facility managers to collect and view relevant data from various systems in one central platform; BIM. It also allows them to adjust their maintenance plans based on the poor behavior of specific spaces within their building.

KEYWORDS: IFC, Predictive Maintenance, BIM, BEMS, CMMS, Energy Performance

REFERENCE: Firas Shalabi, Yelda Turkan (2020). BIM-energy simulation approach for detecting building spaces with faults and problematic behavior. Journal of Information Technology in Construction (ITcon), Vol. 25, pg. 342-360, DOI: 10.36680/j.itcon.2020.020

COPYRIGHT: () 2020 The author(s). This is an open access article distributed under the terms of the Creative Commons Attribution 4.0 International (https://creativecommons.org/licenses/by/4.0/), which permits unrestricted use, distribution, and reproduction in any medium, provided the original work is properly cited. 


\section{INTRODUCTION}

Buildings are responsible for $30 \%$ of the global energy consumption (IEA 2008). Heating, Ventilation, and Air Conditioning (HVAC) accounts for approximately $40 \%$ of buildings' energy consumption (USDOE 2011). However, $5 \%$ to $20 \%$ of HVAC energy consumption goes to waste due to faults and lack of maintenance (Roth et al. 2005). Therefore, it became even more important for facility managers to find more efficient ways for managing building energy (Bush and Maestas 2002). However, facility managers face many challenges to achieve their goals (Jensen and Tu 2015) that includes identifying problematic spaces in a facility in an efficient manner, isolating different types of problems, prioritizing their impact, and developing solutions for these problems (Zhu 2006).

Energy simulations can be very effective to help reduce energy consumption in buildings (Kim et al. 2016). However, building energy analyses are mostly conducted during design stages, and the results of these analyses are not typically used during building operations. Facility managers' ability to identify problematic areas and isolate problems is limited due to numerous interconnected Facility Management (FM) systems and their multilayer information content. Nevertheless, Building Information Models (BIM) provide facility managers with an opportunity to manage and coordinate the information collected from these systems. In addition, it supports engagement of multiple stakeholders, and enables collection of various information throughout the project life cycle.

This study proposes a new BIM-centric framework that enables identification of building spaces with undesired energy performance and support facility managers to provide proper maintenance in an efficient manner. It evaluates the energy performance by comparing Building Energy Management Systems (BEMS) monitoring data with energy simulation results within the BIM environment. In this framework, BIM coordinates data collected by BEMS, geometry data stored in BIM, maintenance data stored in Computerized Maintenance and Management System (CMMS), and energy simulation results generated by EnergyPlus ${ }^{\mathrm{TM}}$ based DesignBuilder software. Detailed tasks include (1) establishing a methodology to collect BEMS data and use it for energy simulations, and (2) developing a framework to identify building spaces with problematic behavior and specifying possible causes. To assess the feasibility of the framework, data was collected from an unoccupied building where areas with problematic behavior were located, and possible causes were identified using its maintenance history data.

This paper is organized as follows: a comprehensive literature review on BIM for building energy management, building energy management systems, BIM for FM, and current maintenance practices is provided in the next section. The framework is detailed in the following section. The next section then presents the results of the experiments conducted. The last section draws conclusions and discusses future research needs.

\section{LITERATURE REVIEW}

\subsection{BIM for building energy management}

Energy modeling is a complex and time consuming task (Crawley et al. 2008; Hong et al. 2020; Im et al. 2020; Song et al. 2019) because of the process of gathering and accurately entering the necessary building description data that is required for simulation. Traditionally, the modeler enters all the data manually to describe the building. It is important to note that the modelers make simplifications on the proposed building geometry to minimize the complexity of the energy modeling and information gathering. Programs such as DOE-2.2 and EnergyPlus ${ }^{\mathrm{TM}}$ that were developed and used to predict energy consumption in buildings require laborious data entry and are complex to learn and use (Heiple and Sailor 2008, Zhu 2006; Kim et al. 2019). Currently, BIM is used to efficiently plan, design, and construct buildings. Energy modeling requires data such as R-values, conductivity and thicknesses, and BIM provides a database that can include such data (Shalabi and Turkan 2016) for all building elements such as exterior and interior walls, roofs, windows, doors, floors, as well as their orientation.

Different energy simulation accuracy levels can be achieved based on BIM Level of Details (LOD). The most accurate simulation can be achieved after completing the building design and finalizing the construction decisions. When used with other Facility Management (FM) systems, conducting energy simulations while operating the building not only helps in detecting energy overconsumption, but also helps define causes for that 
overconsumption (Al-Shalabi and Turkan 2015). Such causes may include lack of maintenance for one or more building elements, users' behavior, or both. The previous research on BIM for building energy management can be categorized into three groups: (1) studies that developed methods and algorithms to use BIM to predict energy performance depending on the results obtained from energy simulation tools such as DOE and EnergyPlus ${ }^{\mathrm{TM}}$; (2) studies that investigated data exchange between BIM and energy simulation tools; (3) studies that developed applications for using BIM for energy management.

The first group focused on developing BIM based methods and algorithms for energy modeling during design phase (Farzaneh et al. 2019). Cho et al. (2010) developed a strategy that uses BIM technology to include sustainable fixtures in energy generation prediction. Another study focused on optimizing energy performance using a multi-objective generic algorithm that uses the results from BIM-based energy simulation (Chen and Gao 2011). Raheem et al. (2011) used BIM to analyze the annual energy consumption and $\mathrm{CO}_{2}$ emissions of a single house. Kim et al. (2013) developed an IFC-BIM based energy simulation process that runs in DOE 2.2. In addition, they developed a semantic material name matching system that finds standardized material names and their associated material property values. Several researchers focused on developing requirements and guidelines for using BIM for building energy modeling and management. Such studies include developing guidelines for using BIM for building energy modeling (Reeves et al. 2012), and studying key BIM-server requirements for information exchange in energy efficient building retrofit projects (Jiang et al. 2012). In a different line of work, Oh et al. (2011) developed a method that uses EnergyPlus ${ }^{\mathrm{TM}}$ and genetic algorithms to determine the optimal design option for various glazing options. In addition, they developed an application to export data from gbXML to EnergyPlus-IDF file. These studies complement and fall within the same scope of the study presented here in terms of developing the energy models using BIM. However, this study differs from the previous work by focusing on using BIM and energy simulations for actively managing building energy performance during building operation phase.

The second group investigated information exchange between HVAC systems and energy simulation tools (Kamel and Memari 2019). Bazjanac (2008) investigated the interoperability between IFC-BIM and building energy analysis tools. This work focused on transferring geometry and HVAC information from IFC-BIM into EnergyPlus ${ }^{\mathrm{TM}}$. O'Sullivan and Keane (2005) presented a graphical user interface to input necessary data about HVAC systems into BIM-based building energy simulation tool using IFC format. These studies are similar to the work presented here in terms of the methods they use to develop the energy model. However, they differ from this study as they developed methods for information exchange, which is not in the scope of this study.

The third group focused on the applicability and usability of building simulation tools in different life-cycle stages of a building (Andriamamonjy et al. 2019). Katranuschkov et al. (2014) developed an energy enhanced BIM (eeBIM) framework with the goal of closing the gap for existing data and tools from building design and operations to enable an efficient life-cycle energy performance estimation and decision-making. Attia (2010) conducted a survey on the selection criteria of building simulation tools among various stakeholders of construction projects, and the results showed a broad range of differences between designers and simulation tools. Difficulties for industry practitioners in implementing BIM are described by Arayici et al. (2011), which included difficulties such as reinventing the workflow, training their staff, assigning responsibilities, and changing the way buildings are modeled. Katranuschkov et al. (2014) described the importance of developing a framework that enables integration of multiple resources (e.g. weather, occupancy, material data, etc.) and the interoperability between energy analysis, cost analysis, CAD, FM and building energy monitoring tools. They also highlighted the importance of combining various construction and FM related data in a typical BIM to be efficiently applied to tasks such as energy simulations and various FM tasks. Kim et al. (2016) built on this work by developing a model for mapping IFC-BIM material information to building energy analysis. Shalabi and Turkan (2016) developed an approach for optimizing data collection from IFC-BIM to be used for corrective maintenance actions. However, none of these studies considered using energy simulation techniques for energy management during building operation phase. This study builds on the work in this group by developing an approach that integrates energy simulation results, actual energy performance monitored by BEMS, and other FM data such as maintenance to move toward a more active building energy management and maintenance. 


\subsection{Building energy management systems}

BEMS adjust and control buildings' HVAC and lighting equipment to manage their environment while optimizing their energy performance and occupants' thermal comfort. BEMS is defined as a collection of microcomputer systems consist of Direct Digital Controllers (DDC) and their control devices, which operate under supervisory control equipment and software collectively. Their capabilities include data sharing with individual controllers for coordination and optimization, linking control processes, and performing operation tasks and reports (Doty and Turner 2012). BEMS is connected to building sensors and controllers that report any flaws or dysfunctions in the system or its equipment.

Building controllers send feedback to BEMS or Building Automation System (BAS) if any of the equipment is not working properly. Facility managers receive alarms from BEMS about any dysfunctions or failure, and they can monitor, change any benchmark, or override the system decisions. When maintenance or replacement is needed, facility managers' report the problem to the maintenance personnel, who would in turn typically search the CMMS to locate, inspect, and gather the required maintenance information regarding that element.

Facility managers work to achieve and maintain the planned operational performance of buildings, and to guarantee an up-to-date maintenance status of the HVAC equipment, which is dependent on the continuous feedback from the building sensors, controllers, and energy management strategies during building operation phase. Energy performance of buildings deteriorates overtime due to several reasons including lack of prompt response to faults and alarms reported by BEMS systems, imprecise commissioning, and BEMS malfunctioning. This would result in energy waste, and cause occupant discomfort and complaints (IFMA 2013).

BEMS reports several types of data that are recorded by FM information systems. The data reported include weather and energy use (e.g., temperature, $\mathrm{CO}_{2}$, zone airflow, daylight levels, occupancy levels, etc.), alarm monitoring and data collected from sensors (e.g., equipment failure, high and low temperatures defective sensors and communication problems), and controllers (e.g. air handler unit controllers, valve controllers and fan controllers) (Doty and Turner 2012). Typically, DDCs are numbered and organized based on their type, function, and location in the building, and presented in list format. However, data about their exact locations, the equipment affected by them and their maintenance history information are stored in different systems. Furthermore, building performance metrics such as sensor outputs, and energy performance metrics are presented in 2D histograms, tables, and lists of tasks or in similar formats, which requires tedious data extraction and interpretation processes to benefit from this data.

A BEMS hosts the results of Fault Detection and Diagnostics (FDD) analysis and presents it to facility managers (Dong et al. 2014). Several FDD approaches have been developed to identify faults and deterioration in building equipment (Dong et al. 2014, Qin and Wang 2005, Sallans et al. 2006, Schein et al. 2006, Wang and Xiao 2006, Xiao 2004). This study differs from FDD approaches as it analyzes energy simulation results using real weather data measured by the building systems and then compares the results to actual energy performance of a building.

\subsection{BIM Implementation in FM}

FM personnel manage HVAC systems and other building components using multiple systems. Their goal is to maintain a thermally comfortable environment for occupants, and to guarantee the functionality of the building while remaining within their operating budget. Two of the major systems used in FM practice are BEMS and CMMS.

FM systems interact with multiple users and stakeholders directly and indirectly during building operations including occupants and FM staff (Roper and Payant 2014). Occupants' actions affect the building energy consumption and the faults reported by BEMS concern facility managers (Doty and Turner 2012). Some wellknown problems caused by occupants include: the use of space heaters during winter that wastes cooling power while increasing the plug loads (Beltran et al. 2013), and blocking of thermostats and sensors with furniture or appliances, which gives false readings to FM systems. The lack of manpower in FM affects maintenance and energy consumption of a building greatly (Roper and Payant 2014, Teraoka et al. 2014). As a result, building operators feel overwhelmed by the number of fault alarms they need to address, thus they focus only on critical faults and complaints made by occupants. Furthermore, facility managers may find temporary fixes that resolve the issue temporarily but lead to more energy waste or allow for other related faults to emerge (Teraoka et al. 2014). 
Throughout facility life cycle, BIM supports a multi-domain and multi-layer collaborative approach, and engages multiple stakeholders in the project including architects, engineers, contractors as well as facility managers and operators. Using BIM leads to decreased information loss during a project's lifecycle (Eastman et al. 2011, AlShalabi and Turkan 2015). Effective sharing of data between various stakeholders is among the capabilities of BIM, which has been proven for design and construction phases. However, effective use of BIM for operations and maintenance phase have not been achieved yet, thus BIM adoption in FM is still in its early stages (Kelly 2013). This is mainly due to the limited awareness among FM professionals about the expected BIM benefits for FM, lack of data exchange standards and unproven productivity gains illustrated by case studies. BIM benefits that are sought during operations phase include extracting and analyzing data for various needs to support and improve decision making processes (Azhar 2011). Furthermore, BIM use in FM applications can provide faster access to data and improve the process of locating facility elements via its user-friendly 3D interface, which helps increasing the efficiency of work order executions (Kelly 2013). In addition, carrying BIM from design to operations phase would allow BIM to support all activities throughout the buildings' life cycle (Fallon and Palmer 2007).

Previous research on BIM use in FM developed BIM-based frameworks to streamline the existing processes and systems. Such studies include an augmented reality based system for operations and maintenance (AR-based O\&M) support (Lee and Akin 2011), a 2D barcode and BIM-based facility management system (Lin, Su, and Chen 2012), and a 3D BIM-based facility maintenance and management system (Chen et al. 2013, Lin and Su 2013). These studies compliment the research presented here in terms of streamlining the existing FM processes and systems. However, this study differs from the previous work as it uses energy simulations and energy performance monitoring to improve building energy management by detecting systems' dysfunctions.

Several other studies developed BIM-based approaches to replace current processes to capture, store, and retrieve facility data in an efficient manner. Such studies include using BIM to generate customized templates to capture maintenance work related changes (Akcamete 2011), a knowledge based BIM system that uses casebased reasoning for building maintenance (Motawa and Almarshad 2013), fault-tree analysis for failure root cause detection (Lucas et al. 2012, Motamedi et al. 2014), and using BIM for HVAC troubleshooting (Yang and Ergan 2015). However, none of the studies in this group focused on developing an approach to provide facility managers with solutions that are proactive to improve the performance of their buildings.

While BIM is sought to benefit FM practice, there are still many challenges regarding BIM implementation in FM. Two of the major challenges that prevents BIM implementation in FM include unproven productivity gains that can be realized from reduced equipment failure, as well as the productivity increases that may be realized through an integrated platform (Becerik-Gerber et al. 2011). Furthermore, fragmented data, data interoperability, and lack of data transparency throughout the building life cycle are among some of those challenges.

\subsection{Maintenance in FM}

Maintenance can be preventive, corrective, or predictive. Corrective maintenance is considered as reactive type of maintenance that responds to a failure or to a breakdown (Motawa and Almarshad 2013). Preventive and predictive maintenance are considered as proactive maintenance that prevents a failure or a breakdown of building equipment (Palmer 1999). Preventive maintenance is scheduled and predefined for regular intervals to guarantee a continued optimal performance (Rikey and Cotgrave 2005). Unlike corrective maintenance, preventive maintenance reduces non-planned work and allows estimating the overall maintenance budget (Flores-Colen and de Brito 2010). Predictive maintenance is a condition-based maintenance that is useful for reducing life-cycle costs and achieving more efficient maintenance budgets (Hermans 1995). Corrective maintenance is usually an emergency action that leads to unavoidable extra costs. It is important to minimize the occurrences of this type of maintenance (Flores-Colen and de Brito 2010). The framework described in this paper aims to help achieve predictive maintenance benefits and reduce corrective maintenance occurrences.

\section{BIM-CENTRIC FRAMEWORK FOR DETECTING BUILDING SPACES WITH FAULTS AND PROBLEMATIC BEHAVIOR}

Facility managers depend on various facility management systems to operate their buildings efficiently, with minimum shutdowns. Due to the complexity of buildings, the massive amount of data collected from facility management systems, and the multiple factors such as normal wear and tear in building elements, building users' 
behavior, and degradation in equipment that affect a building's performance, it has become cumbersome for facility managers and building operators to identify and specify spaces with abnormalities or malfunctions in buildings' systems.

The main objective of the approach described here is to detect building spaces with abnormalities or malfunctions in buildings' systems that are causing excess energy consumption, human discomfort, or work overload on HVAC systems. The nature of such faults is usually hidden and undetected by BEMS alarm systems. However, such faults affect the heating and cooling equipment's energy consumption remarkably. Therefore, the focus of this study is on developing a BIM-centric framework that integrates data from BEMS and CMMS systems as well as energy simulations, which enables identification as well as visualization of spaces with heating and cooling equipment that are not functioning properly, i.e. over consume energy, in the BIM environment.

Corrective maintenance actions are critical for building performance as such faults in building systems may cause losses in equipment, affect occupants' comfort, and result in unexpected maintenance or replacement costs. The framework described in this paper enables identification and visualization of building spaces with degraded or malfunctioning equipment while also providing information on maintenance history of those equipment in BIM environment. Since BIM is not all-inclusive, data can be aggregated from other FM systems as needed and included in BIM (Figure 1). This would allow facility managers to compare, analyze, and visualize information collected from various FM systems to identify and visualize any faults in building systems and their potential causes.

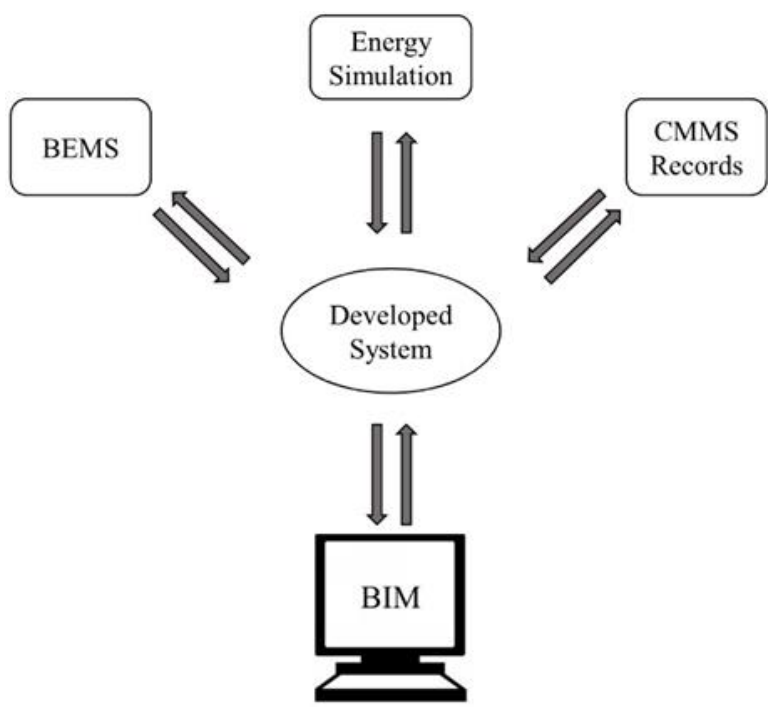

FIG. 1: Role of BIM in the Framework.

As mentioned above, BIM coordinates three different types of data, namely outputs of BEMS, CMMS, and energy simulations. BEMS records and keeps interior and exterior weather data that are considered essential to run accurate energy simulations. In addition, it records heating and cooling patterns by controlling heating and cooling outlets such as radiators' valves, Terminal Air Boxes (TAB) fans speeds, and fresh air intake. BIM can store valuable and essential information including energy simulation output data, building geometry, material properties, walls assembly, properties of HVAC systems and components, as well as building operation strategies and schedules (Katranuschkov et al. 2014, Kim et al. 2016, Maile, Fischer, and Bazjanac 2007). In this study, BIM stores and visualizes data input from BEMS and CMMS systems as well as energy simulations to determine building equipment's behavior and maintenance needs.

In this study, the complexity of the studied building and its systems were the determining factors in choosing EnergyPlus over other energy simulation tools such as TRNSYS or eQuest. EnergyPlus enables defining building components in detail, and it is capable of combining multiple systems in the simulation, thus providing more realistic simulation results. EnergyPlus has proven its reliability in modelling multi-zone buildings from public housing (Xu et al. 2014) to airports (Griffith et al. 2003). 
Developing and validating an energy model of a multi-zone building can be a challenging task. In this study, the energy modeling process was conducted in three stages. The first stage involves acquiring or developing a 3D as-built geometry of the building. Since there was no readily available 3D as-built model of the studied building, the research team built one from its LiDAR data (3D point cloud) to guarantee an accurate model that closely represents the as built conditions (this process is commonly referred to as Scan-to-BIM) (Bosché et al. 2015, Volk et al. 2014). The data collected include locations of all architectural elements, HVAC elements, pipes, electrical plugs, sensors and thermostats. The second stage involves collecting non-graphical data of the building materials and systems. Such data include detailed envelope composition, material properties, O\&M manuals, nominal powers for main HVAC system components such as the boiler and the Air Handling Unit (AHU), and schedules for equipment and occupants. Stage three involves adding weather data from the local weather station that is located on the roof of the studied building, which is connected to the BEMS, as well as adding the information included in the commissioning documents to the energy model, and finally calibrating the energy model with the as-designed energy model. The reason behind the calibration process is to ensure the accuracy of the generated energy model.

Figure 2 presents the framework consisting of three major levels that are detailed below.

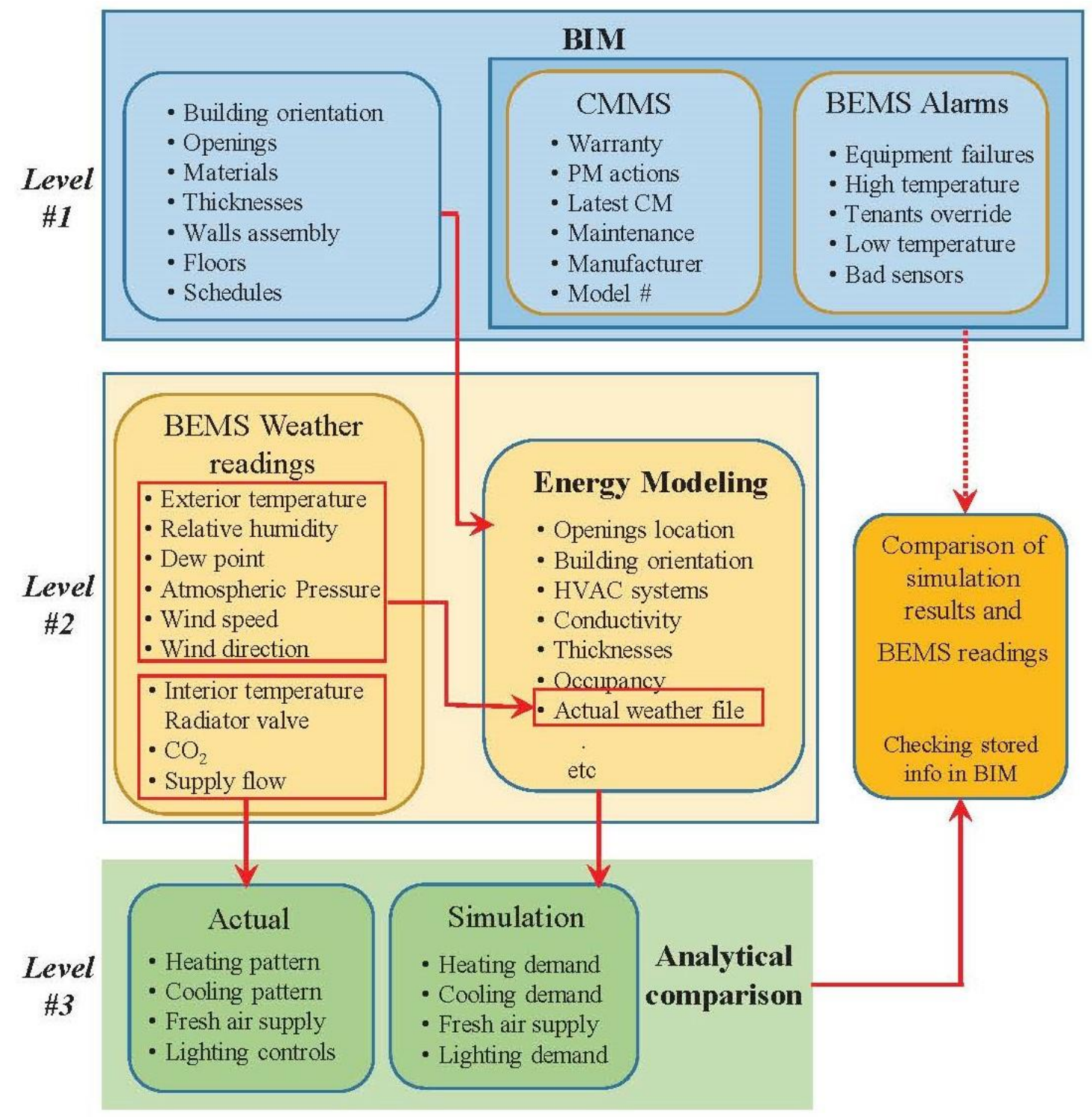

FIG. 2: Overview of the Framework. 
- Building Information Level: At this level, building data is collected, retrieved from different systems, and stored in BIM as detailed in Shalabi and Turkan (2016). It includes building geometry, materials and assembly, BEMS alarms, and CMMS data. Building geometry and assembly information are typically stored in BIM, while BEMS and CMMS data needs to be collected and temporarily stored in BIM to identify building spaces with equipment that is not functioning properly.

- Energy Simulation Level: Weather data that was collected and stored by BEMS in the previous level is used at this level. The weather data includes exterior dry bulb temperature, relative humidity, dew point, atmospheric pressure, wind speed, and wind direction. This data is used to create the weather file that is needed to run the simulation. In addition, building information including building orientation, openings, HVAC systems, material conductivity, wall assembly, and thicknesses from the previous level is used to develop the energy model. The energy simulations are then performed, and the results are reported to the next level.

- Analytical Comparison Level: At this level, actual heating and cooling patterns are compared with heating and cooling load results of energy simulations obtained for each space. A discrepancy or a major flaw between the two highlights the need for a closer observation of that particular space. This will allow facility managers to have a better idea about the potential causes of the fault since they will be looking at a specific area depending on the nature of the simulation result and the information collected from BEMS and CMMS.

\subsection{Level 1: Building Information Aggregation}

Data and information from multiple systems are needed to manage and operate a facility. In this framework, building geometry and material data are stored in IFC-BIM from the handover and commissioning phase. All thermal properties of wall assemblies can be stored in IFC-BIM as IFC-PROPERTY-SET with different properties as IFC-PROPERTY-SINGLE-VALUEs. Such data is automatically generated by a BIM software (e.g. Revit) when provided during the modeling process. Data that are collected from other systems, such as BEMS and CMMS, are first exported into Excel format manually, and then aggregated into IFC-BIM automatically. Accurate evaluation of building equipment energy consumption requires recording local weather measurements, which is the norm in most modern BEMS systems. Therefore, three types of data are exported from the BEMS including alarms caused by equipment faults, actual heating and cooling system loads, and weather data (e.g. external dry bulb temperature) and utilized in BIM and energy modeling process. Figure 3 illustrates this level in detail.

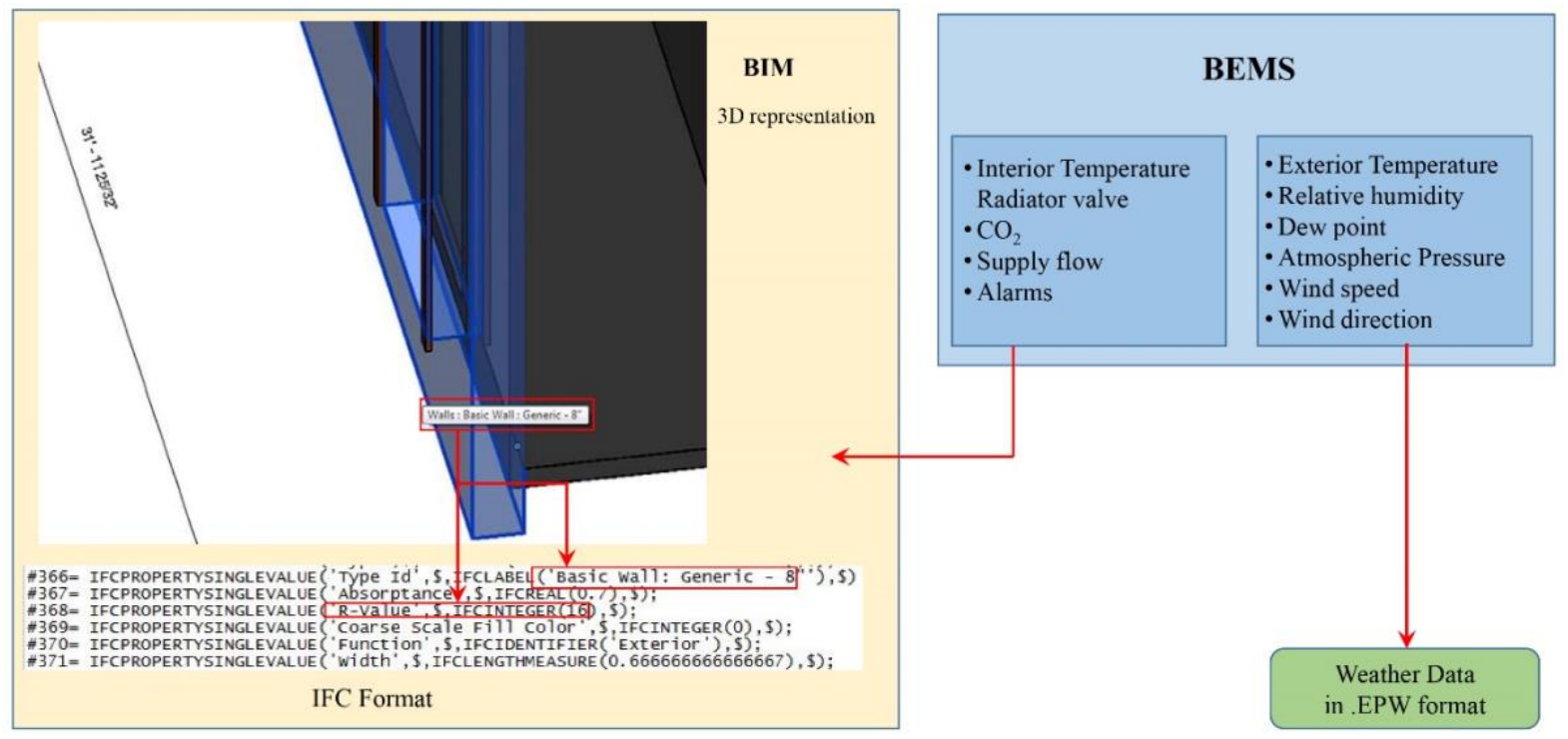

FIG. 3: Level 1 - Aggregation of Building Information. 


\subsection{Level 2: Building Information Aggregation}

Energy simulation tools such as EnergyPlusтm and DOE-2.2 are dependable but not very user-friendly tools. At this level (Figure 4), data collected from other systems and stored in BIM are used to develop the energy model. The energy simulation tool is capable of utilizing properties of the building envelope such as wall thicknesses, assemblies, and different conductivity values from IFC-BIM. In addition, various occupancy schedules and densities are input into the energy simulation tool. Typically, all occupancy schedules and densities are taken from class schedules, which are updated every semester. However, the studied building was unoccupied at the time of data collection. Thus, such data was not included in the energy simulation in this study. EnergyPlustm based user interface software DesignBuilder was used to run the energy simulations.
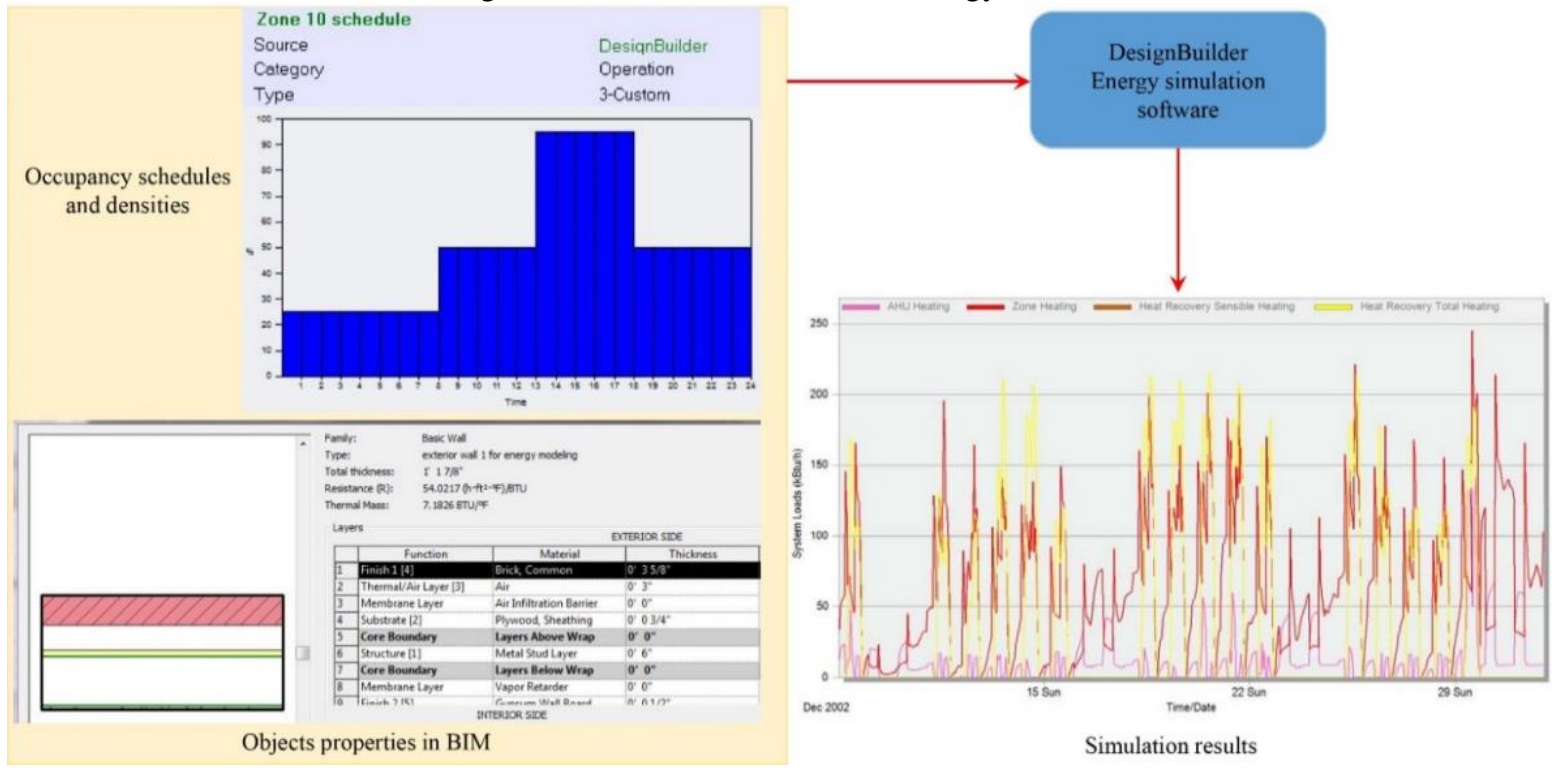

FIG. 4: Level 2 - Energy Simulation Level.

HVAC thermal zones are divided into smaller spaces reflecting the actual HVAC outlets (e.g. TABs and radiators). This simulation, corresponding to the actual as-built BIM data that uses actual occupancy schedules and densities (which is an empty building in this case), differs from the energy simulation that is conducted during design stage at macro level. The energy model used for this simulation is tuned to match the actual operating schedules and the various set points (e.g. temperature, humidity, $\mathrm{CO}_{2}$, etc.) of the BEMS that controls the building's climate.

\subsection{Level 3: Analytical comparison}

A certain amount of energy is needed to heat or cool a given building space. Energy simulations utilize building operation and BEMS schedules to produce detailed energy consumption loads, i.e. separate heating and cooling loads, for each building space with a HVAC outlet. For the HVAC system, each energy outlet, such as a radiator or a cooling air duct, will diffuse a certain amount of energy either through heating or cooling the space. This amount is controlled by the BEMS. Furthermore, the BEMS tracks the duration and amount of energy used for each HVAC equipment such as the amount of energy provided by heating radiators. Building energy simulations utilize the same information that is fed into the BEMS. Depending on this information, the energy model will simulate the proposed energy outcome for each of the outlets, and for each outlet, the simulated energy amount will be compared to the consumed amount. The system will define the discrepancies and each discrepancy will be flagged. The system will aggregate CMMS and BEMS to present relevant information about the HVAC equipment for the spaces with discrepancies. The final analysis and decision-making falls on the facility manager.

After performing an analytical comparison between the results, the following scenarios can be considered (Table 1). The first scenario deals with cases demonstrating a constant or unresponsive behavior; i.e. the heating or cooling outlet is not corresponding to the changes of heating and cooling demand. This may suggest a malfunctioning valve, a broken controller or an operator override. The second scenario corresponds to cases with 
above normal behavior, i.e. the heating or cooling outlet responds to the demand but excessively. This may suggest an occupant behavior such as opening a window, a piece of furniture blocking a radiator, or a set point override in BEMS. The third scenario deals with cases demonstrating a below normal behavior; i.e. the heating and cooling outlet is responding to the demand but insufficiently. In this case, the heating or cooling does not satisfy the space needs. This may suggest broken sensors that reports current temperatures, broken valves in the heating or cooling outlet, or an external heating source that affects the temperature sensors. Finally, scenario four examines irregular patterns; i.e. the actual consumption does not follow a pattern. In this case, the problem can be in the central unit, in the simulation itself, BEMS readings, or BEMS programming. However, the last scenario is not in the scope of this study.

It should be emphasized that this framework is not designed to detect irregular behavior in a specific system equipment to improve FM tasks. Rather, it provides a methodology to monitor, maintain and help reduce energy consumption of a building. The framework does not detect a specific piece of equipment that causes energy overconsumption, however it helps identify which space inside the building is performing poorly and the equipment connected to this space.

Table 1: Analytical comparison outcomes

\begin{tabular}{lll}
\hline HVAC behavior & Explanation & Potential causes \\
\hline Unresponsive & $\begin{array}{l}\text { Constant value and pattern, } \\
\text { no response to change in demand }\end{array}$ & $\begin{array}{l}\text { Malfunctioning valve } \\
\text { Broken controller } \\
\text { An operator override }\end{array}$ \\
\hline \multirow{2}{*}{ Excessive } & $\begin{array}{l}\text { Excessive response to the heating } \\
\text { and cooling demand }\end{array}$ & $\begin{array}{l}\text { Occupant behavior } \\
\text { Furniture blocking the HVAC outlet } \\
\text { A change in the set point }\end{array}$ \\
\hline \multirow{2}{*}{ Insufficient } & $\begin{array}{l}\text { Insufficient heating or cooling is } \\
\text { provided to the space, but it follows } \\
\text { the demand pattern }\end{array}$ & $\begin{array}{l}\text { Broken sensor } \\
\text { Broken valve or its controller } \\
\text { External heating source }\end{array}$ \\
\hline Irregular & Not following the demand & Out of scope \\
\hline
\end{tabular}

\section{EXPERIMENTAL RESULTS}

\subsection{Building Description}

King pavilion is a two-story 15,228 sqft educational building housing design studio for architecture students at Iowa State University. Figure 5 presents its 3D view generated with DesignBuilder. The building is divided into 15 working spaces and is heated by a central boiler and is cooled by a central chiller. Every space is connected to a separate heating radiator and TAB to heat, cool, and ventilate the space (Figure 6). In each space, there are sensors measuring humidity, dry bulb temperature, and $\mathrm{CO}_{2}$ for mechanical ventilation. All fifteen spaces are in the same thermal zone.

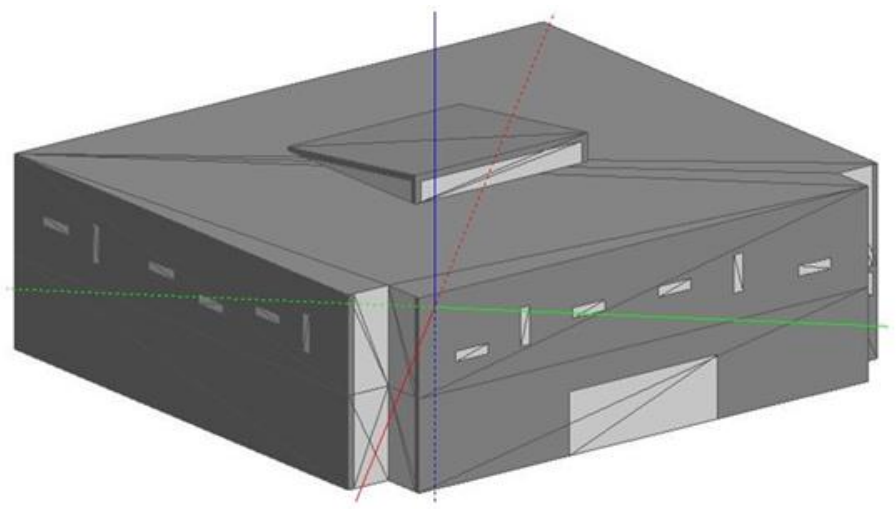

FIG. 5: 3D BIM of the Building. 

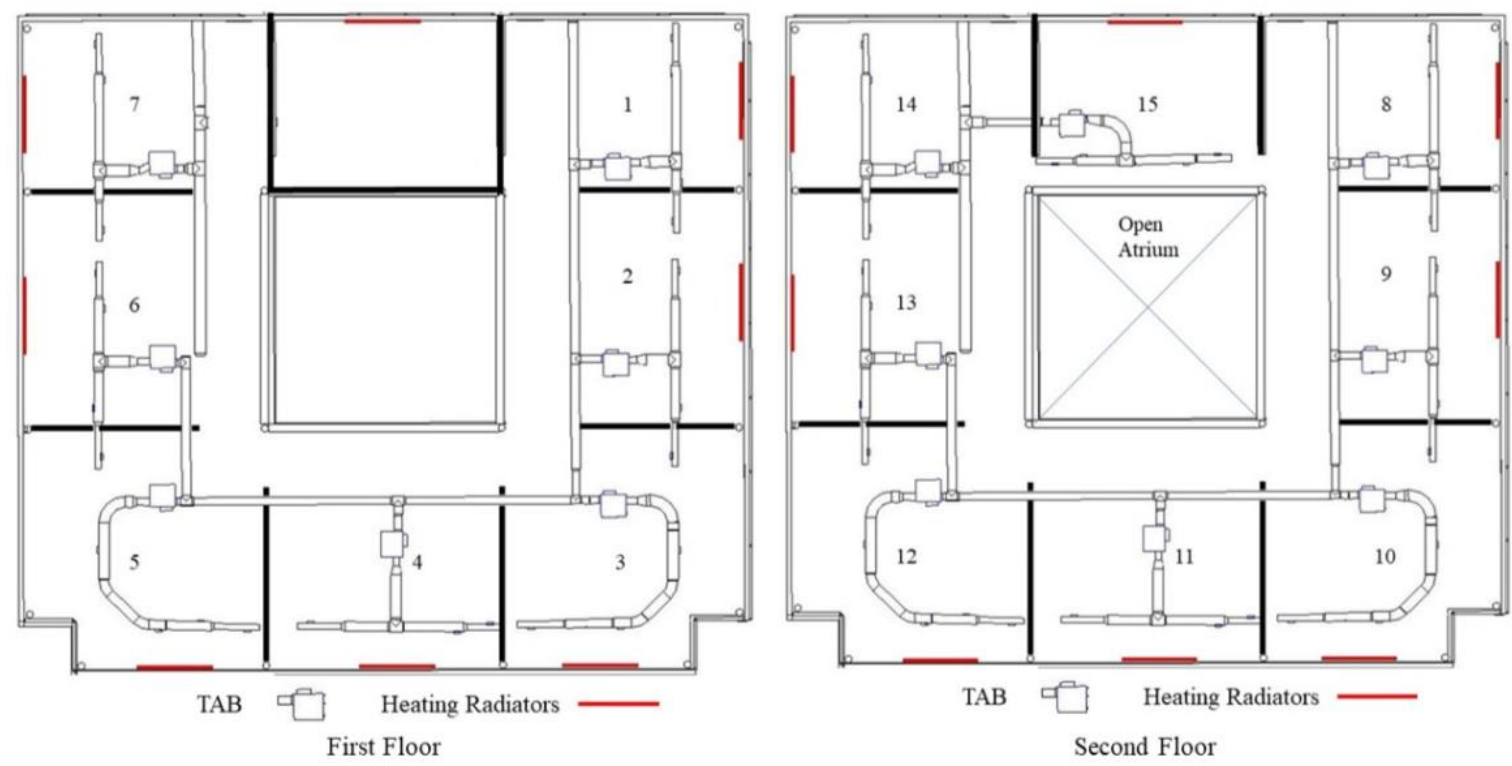

FIG. 6: King Pavilion Floor Plans with TABs and Heating Radiators Locations.

Geometric information for the BIM of this building was developed from its laser scan point cloud captured using a Trimble TX5 laser scanner (Trimble 2012). Eight separate scans were taken to cover each floor of the building, sixteen scans for the whole building. Autodesk Revit Scan-to-BIM plugin, a semi-automated modeling tool, was utilized to model HVAC and structural components from the point cloud accurately. In addition to the laser scans, several measures were employed to ensure an accurate representation of the building as is. Such measures include: (1) design reports and LEED documents provided by the architect. (2) Extensive surveys to capture and validate physical construction, equipment utilization, and reviewing the BEMS logs.

\subsection{HVAC System}

The building is heated with hot water radiators. The water is heated by a central boiler that serves multiple buildings on campus. The BEMS controls the hot water flow in the radiators. The required flow is based on a fixed set point that can be adjusted by the facility manager. The hot water is supplied to the radiator at a max of $215 \mathrm{~F}^{\circ}$ measured at the central boiler unit and this is the temperature assumed for calculating the actual demand. The radiator heating capacity is $1300 \mathrm{BTUH} / \mathrm{ft}$. The building is connected to one main AHU that is connected to a thermal wheel to recover waste heat. This arrangement eliminated the need for heating coils within the AHU, which provides a conditioned ventilation air by a central single-duct forced-air system.

Sensible cooling is provided using the central water chilling system that is connected to the AHU in the building. The chilled water temperature ranges between 50 and $55 \mathrm{~F}$. Its flow rate, through the AHU, varies according to the sensible cooling load. Each space in the building has a separate TAB that is connected to a valve and a vent that controls the amount of cool air provided to each specific place depending on the cooling load. This study focuses on heating; therefore, no cooling equipment or strategies are included in the analysis.

Material data that is captured from the handover documents and the building commissioning verification results was uploaded to the BIM and then to the energy simulation software. Thermal properties imported from the BIM into EnergyPlus include thermal properties of architectural elements such as Emittance, Permeance, and Resistance $(R)$ values and characteristics of the HVAC system (Table 2). Weather data for the energy simulation were recorded onsite using the sensors of the BEMS systems. Based on those sensor readings, BEMS react and operate the heating and cooling equipment in the building.

The energy simulation parameters were set according to the actual measured parameters under which the building is operated. The building is divided into fifteen spaces. Each space includes a hot water radiator, vents, and a TAB. Each TAB contains $\mathrm{CO}_{2}$, relative humidity and dry bulb temperature sensors that read measurements of the returning air. All these details were included in the EnergyPlus simulation model. 


\begin{tabular}{|c|c|c|}
\hline $\begin{array}{l}\text { Building envelope } \\
\text { components }\end{array}$ & Description & Thermal properties \\
\hline Exterior walls & $\begin{array}{l}\text { Composite wall system, frame, masonry, } \\
\text { concrete, insulation, cladding }\end{array}$ & $R-19_{(1)}$ \\
\hline Roof & $\begin{array}{l}\text { Concrete, insulation entirely above deck, } \\
\text { composite }\end{array}$ & $R-16$ \\
\hline Floor/Slab & Steel frame, concrete on deck & $R-19$ \\
\hline \multirow[t]{3}{*}{ Windows/Doors } & Combination of Low-E clear with high & $R-3$ \\
\hline & visible transmittance with aluminum & $R-2 \mathrm{SHGC}_{(2)} 0.62$ \\
\hline & frame & Visibility Transmittance 0.74 \\
\hline Shading devices & Overhangs & \\
\hline HVAC system & $\begin{array}{l}\text { Hot water radiators, VAV system with } \\
\text { gas absorption chiller, gas fired boiler }\end{array}$ & \\
\hline Energy recovery & Sensible Energy Recovery & $94 \%$ effectiveness \\
\hline \multicolumn{3}{|c|}{$\begin{array}{l}\text { (1) } R \text { is measured in }\left(\mathrm{h} \mathrm{ft} 2{ }^{\circ} \mathrm{F} / \mathrm{Btu}\right) \text { which is the hours needed for } 1 \mathrm{Btu} \text { to flow through } 1 \mathrm{ft} 2 \text { of a given } \\
\text { thickness of a material when temperature difference is } 1 \mathrm{~F}^{\circ}\end{array}$} \\
\hline \multicolumn{3}{|c|}{$\begin{array}{l}\text { (2) } S H G C \text { is the Solar Heat Gain Coefficient and represents fraction of incident solar radiation admitted } \\
\text { through a window by direct transmission and by absorption and release into the space. }\end{array}$} \\
\hline
\end{tabular}

The simulation results were compared with the Actual Heating Consumption (AHC) as measured by each radiator valve opening in that specific area or space. The length of the radiator differs from one space to another resulting in a different amount of BTU/h infused in each space. AHC in BTU/h is calculated as follows (Equation1):

$$
A H C=R C \times L \times V \quad(\mathrm{Eq} 1)
$$

Where:

$\mathrm{AHC}=$ Actual Heating Consumption

$\mathrm{Rc}=$ Radiator Heating Capacity

$\mathrm{L}=$ Length of the radiator

$\mathrm{V}=$ percentage $(\%)$ of Valve opening

In 10 spaces out of 15, the heating radiator valve demonstrated regular behavior (Figure 7).

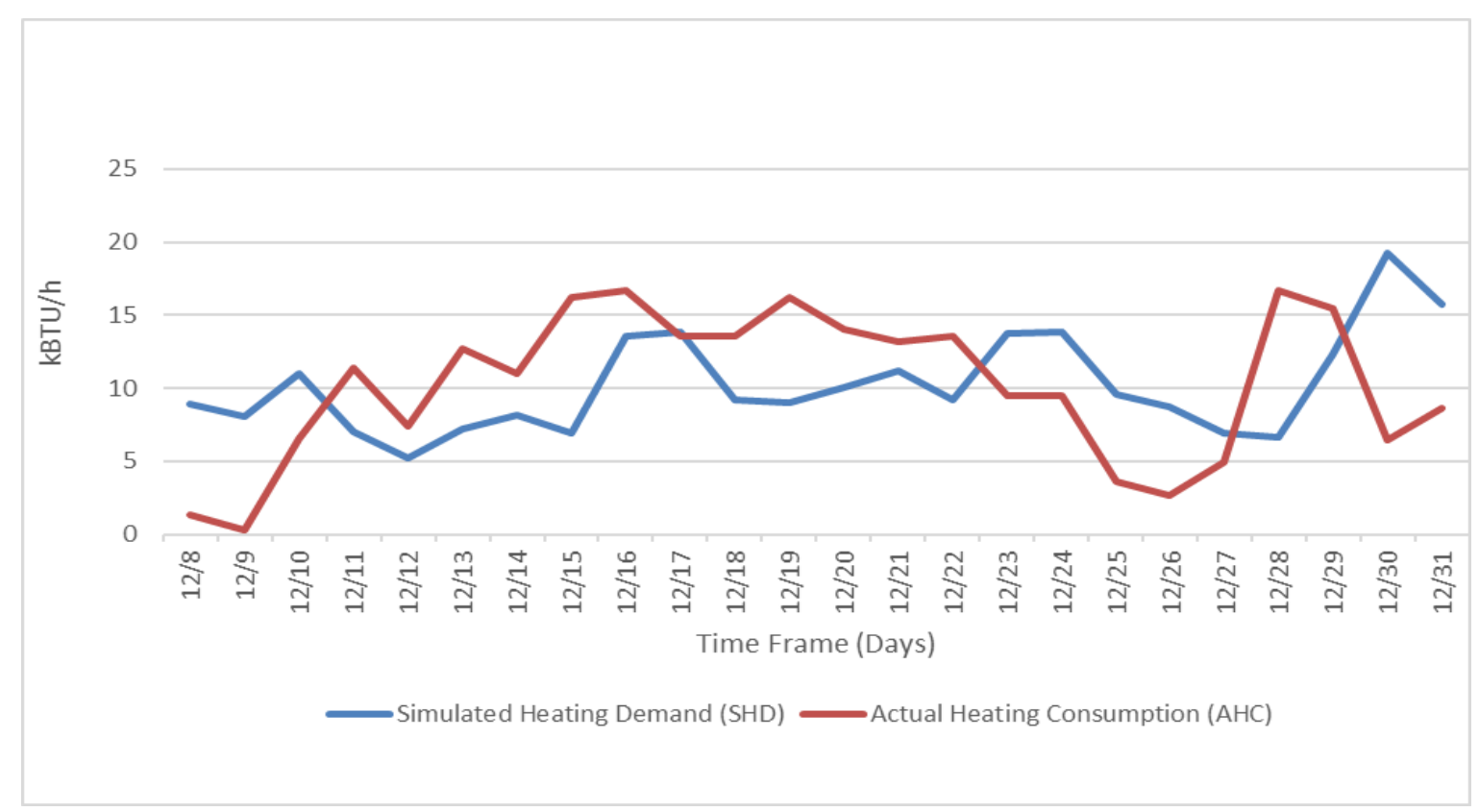

FIG. 7: Actual Heating Consumption vs. Simulation Heating Demand Comparison for Space \#3 
The regular behavior of a radiator valve is defined as the valve response to the change in Simulated Heating Demand (SHD) by either going up or down. Such demand is predicted in this framework using the energy simulation results for a given building or space. A discrepancy is when AHC does not respond in a similar pattern as the SHD or responds completely different, e.g. AHC increases while SHD is decreasing or vice versa.

For Space 3 in Figure 7, the AHC behavior follows the pattern of the SHD with some delay. The ideal scenario is the case when the actual and simulated heating patterns match. However, the average difference between AHC and SHD was $(0.016 \mathrm{kBTU} / \mathrm{h})$ over the testing period of one month with SHD being more than AHC. In the three-week testing period, AHC has not always followed the SHD immediately and took some time to adapt to the change in temperature and heating demand. On $12 / 10$, the average daily temperature increased from $22 \mathrm{~F}$ to $39 \mathrm{~F}$ indicating less heating demand. The SHD responded to this change by reducing the heating demand. However, the AHC acted in opposite manner, reflecting an increase in demand instead. On 12/11, it returned to follow the regular pattern. The system repeated the same behavior on 12/22 and 12/28. On both dates, a sudden change in the average daily temperature occurred and the temperature either dropped or increased significantly. This behavior may indicate a problem with the BEMS itself indicating that a calibration to the system is needed. It can also indicate an external factor that is causing the system to receive false readings. In both cases, a further investigation and more testing is needed to define the causes of the odd behavior. The system developed in this research can define areas with problematic behavior. It also provides the facility manger with a comprehensive approach that allows to define areas and components that need a closer look for maintenance.

Note that when the heating demand increases, the valve opening increases to meet the heat demand, following the demand predicted by the simulation. This adaptation is desired by the heating system as it heats the building as needed. Similarly, the actual valve decreases its opening following the demand predicted by the simulation. Facility managers have access to the AHD in BEMS through 2D graphs, but not the predicted consumption i.e. SHD. Therefore, facility managers cannot compare the data they receive to an ideal behavior and detect undesirable behavior in the system.

On the other hand, 5 out of 15 spaces in the building depicted different behavior that varied between not responding to heat demand variations at all, overheating, or underheating the spaces. In Figure 8, the radiator in Space\#6 did not respond to energy demand variation at all, i.e. radiator valve was closed all the time. The average difference between the AHC and SHD was $(0.6 \mathrm{kBTU} / \mathrm{h})$ over the testing period of 1 month, with SHD being more than AHC. Such behavior can indicate more energy savings in this space but compromises occupants' thermal comfort when the space is occupied or increase the load on adjacent spaces' equipment. A similar behavior was detected in space in Space \#9 (Figure 9), the radiator valve was not able to open more than $5 \%$.

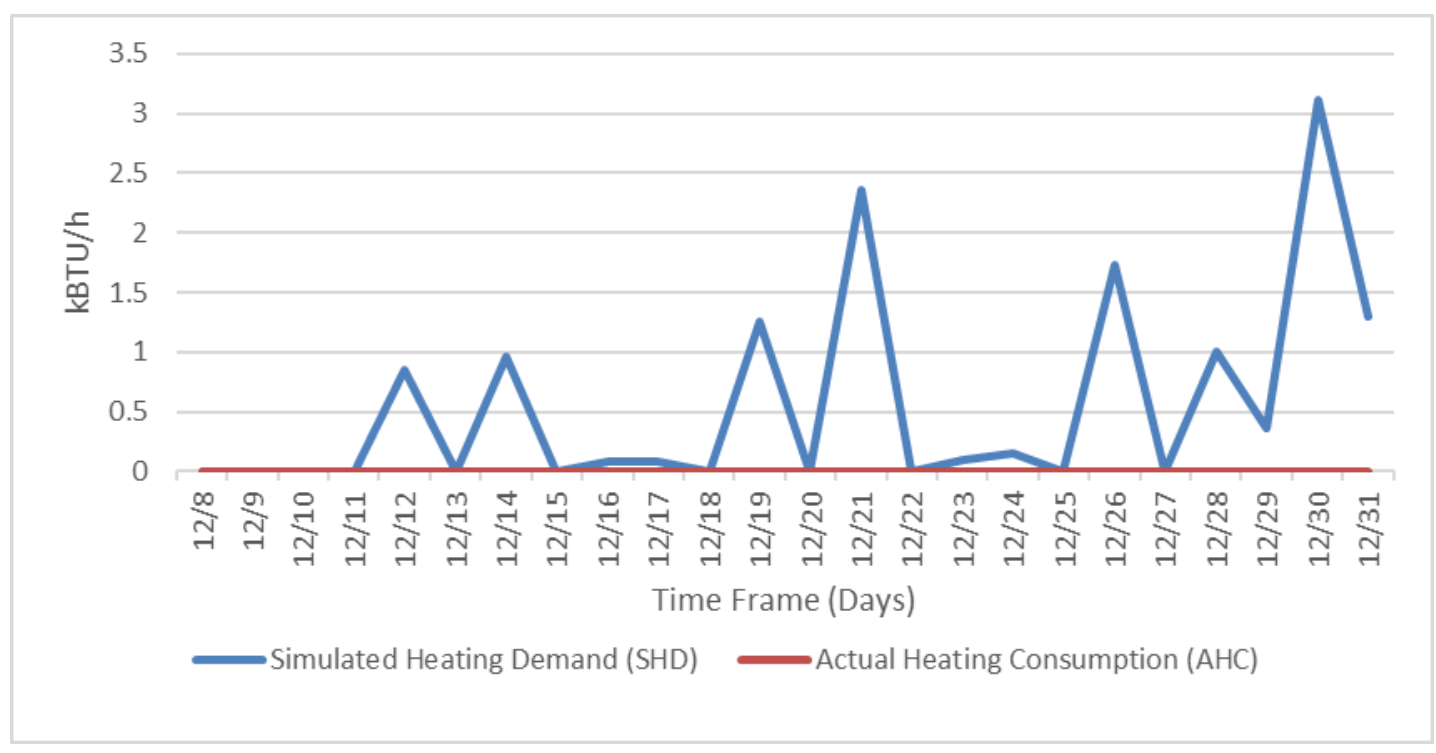

FIG. 8: AHC vs. SHD for Space \#6. 


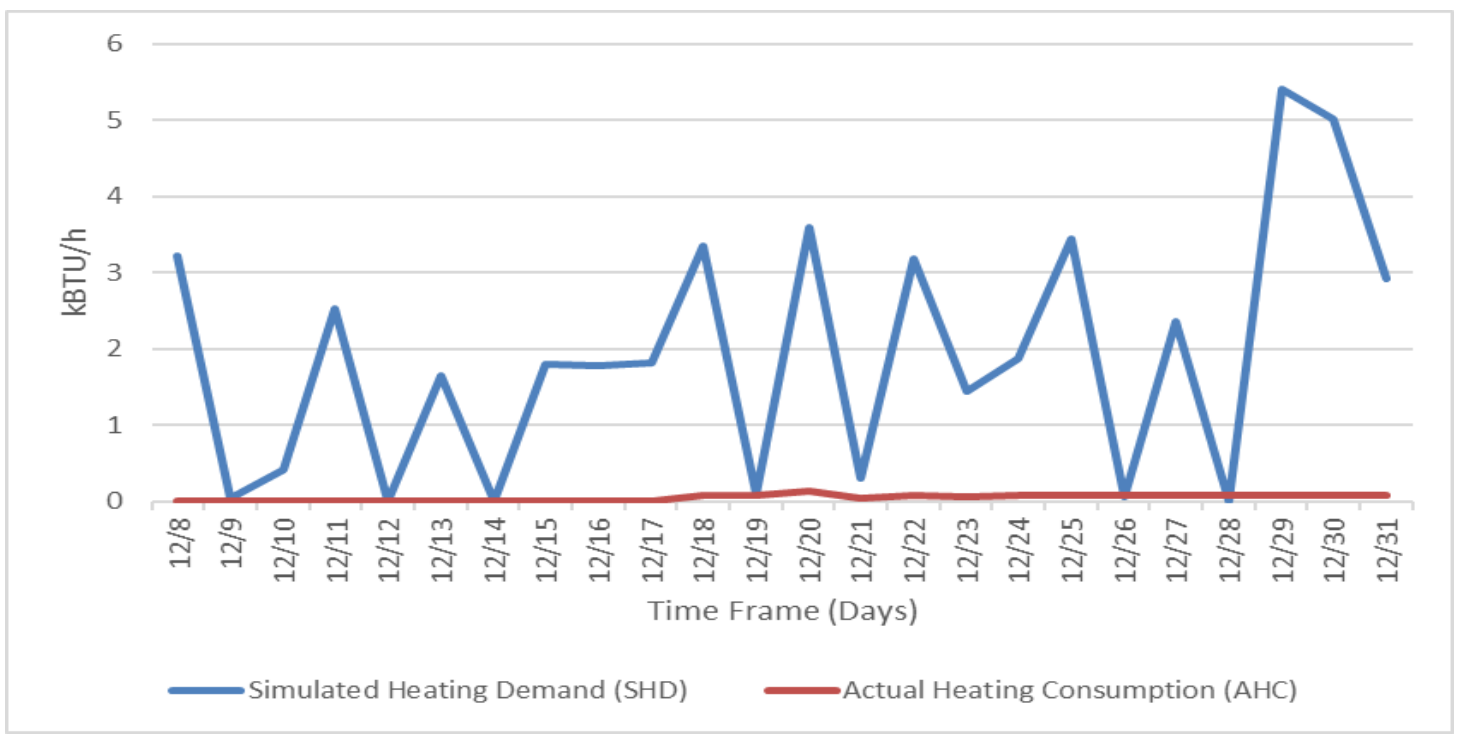

FIG. 9: AHC vs. SHD for Space \#9.

On the contrary, for spaces 7 and 10, (Figure 10) and (Figure 11) respectively, the radiators were overheating both spaces resulting in energy overconsumption. The average difference between the AHC and SHD was 3.86 $\mathrm{kBTU} / \mathrm{h}$ for space \#7 and $2.06 \mathrm{kBTU} / \mathrm{h}$ for space \#10 over the testing period of one month, with AHC being more than SHD. Interestingly, the spaces that were over heated are adjacent to spaces that were under heated. Such behavior directs the facility manager to examine both spaces closely as an undetected fault might be present in the HVAC, sensors or systems of either or both spaces. As mentioned in the methodology section, this framework does not pinpoint the malfunctioning equipment. However, it achieves two main things. First, it provides a proactive approach to energy savings and equipment maintenance in a building as it enables identifying a fault or a problem that is causing energy over consumption that may result in a costly failure in the system. Second, it narrows the search down to a single or small group of spaces that are connected to a limited number of equipment. It should be noted that those problems were not picked up with regular facility management practice, which follows a corrective maintenance approach rather than a predictive one. While such problems seem clear and obvious, they are often overlooked by FM teams and hard to detect in a timely manner. Larger buildings often have more rooms and far more complex systems that cause this process to be cumbersome.

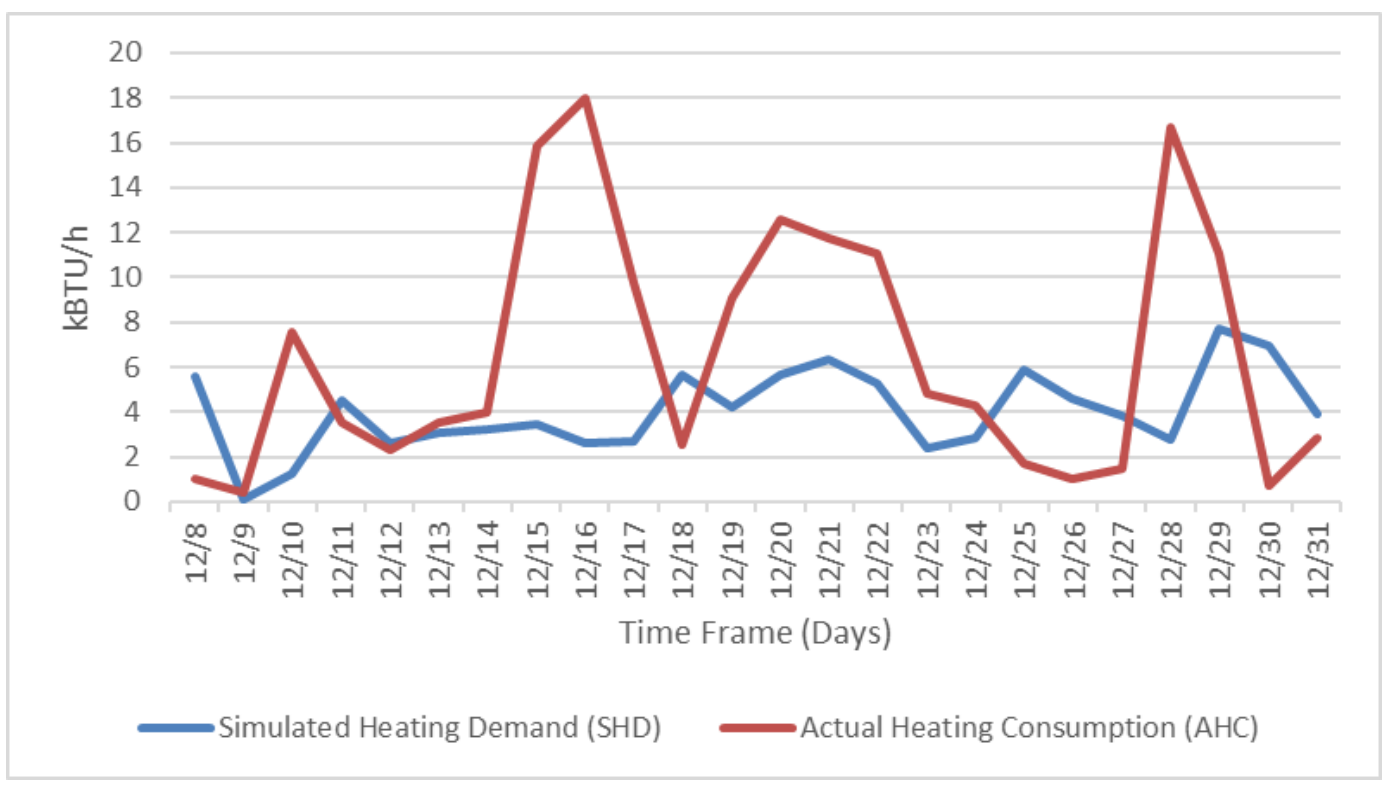

FIG. 10: AHC vs. SHD for Space \#7. 


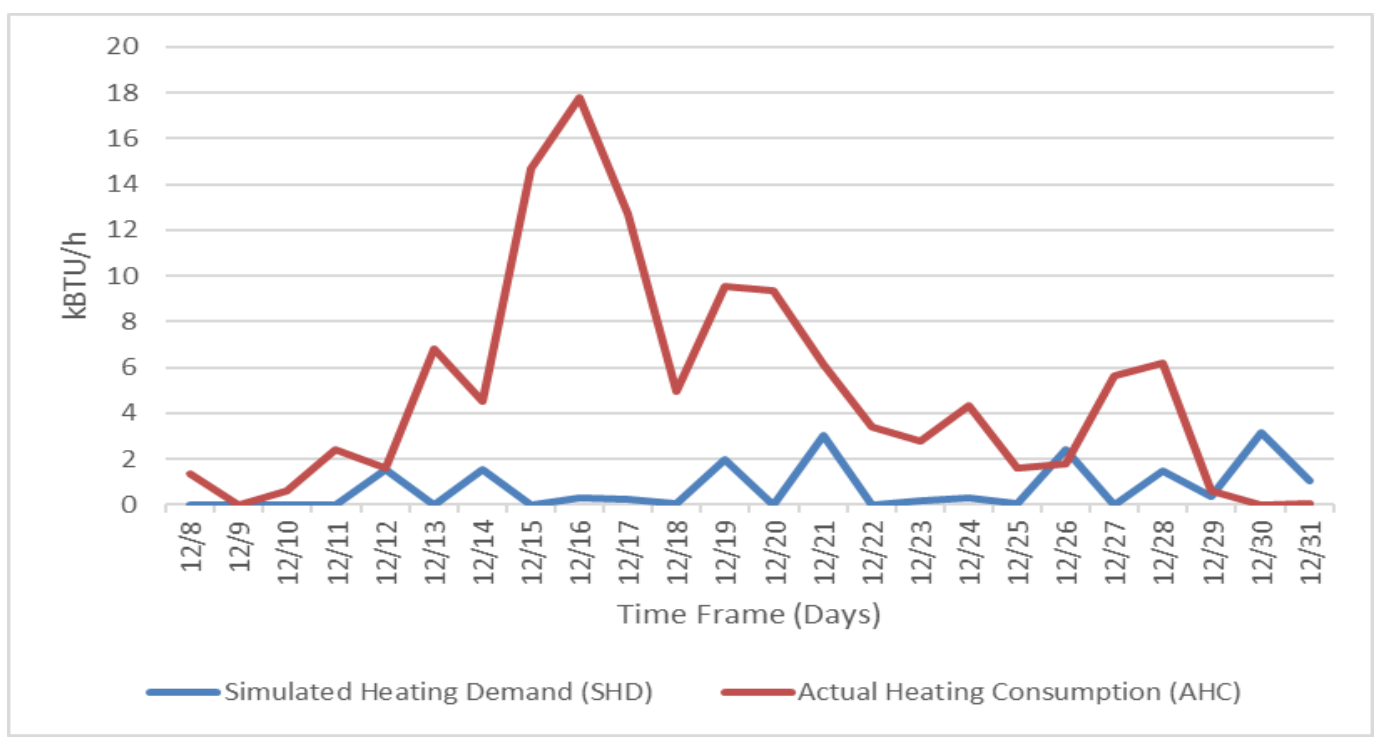

FIG. 11: AHC vs. SHD for space \#10.

This approach provides facility managers with a closer look on how the building equipment and systems are performing at a given time, which enables them to determine spaces that are under or over consuming energy. Facility managers can then analyze that equipment and take actions accordingly.

\section{CONCLUSIONS}

A significant amount of energy is wasted due to faults in HVAC systems and lack of maintenance. Facility managers are aware of the importance of finding efficient ways to manage and reduce the energy consumption in their facilities. Current FM systems are lacking interoperability capabilities and are operated by different teams resulting in poor data coordination and management. In addition, facility managers face challenges in identifying problematic spaces in their facilities, isolating types of problems, and prioritizing the impact of those problems. BIM is capable of coordinating data from different FM and energy management systems, which would provide a comprehensive perspective of building spaces, its equipment, and information to facility managers. Previous studies developed methods that utilize BIM to predict energy performance during design phase; investigated information exchange between BIM and energy simulation tools; and developed methods for energy management during design phase. However, none of these studies focused on using BIM and energy simulation tools to identify and locate problematic spaces in a facility, which is very important for timely maintenance.

This paper presented a framework that utilizes BIM to compare energy simulation results obtained using actual HVAC patterns, historical BEMS and maintenance data. The contributions include 1) a methodology that enables comparing actual HVAC behavior with heating and cooling demand obtained from energy simulation using as-built characteristics of a building 2) a BIM-centric framework that helps identify spaces with undesired energy performance in a building so that timely maintenance actions can be taken. While the framework helps to identify building spaces that are not meeting the energy demand, and enables to gather all relevant information from BEMS and CMMS automatically, it still requires manual rationalizing from facility managers. More specifically, facility managers still need to examine and identify the actual cause of the fault or the problem that is detected automatically by the framework.

The framework was tested on data collected from an unoccupied educational building that includes several design studio spaces. The results showed that the framework enabled detection of problematic building spaces, and identification of potential causes by using the BEMS and CMMS data corresponding to those spaces. However, the nature of the detected faults is not reported by the automated BEMS alarming system. Thus, the cause of such problems requires further investigation by the facility manager. Comparison between the intended energy performance and the actual performance of a building HVAC equipment pinpoints the faults and problems. In this study, the comparison between the actual energy performance and the intended energy performance of the studied building resulted in one of four cases: unresponsive, excessive, insufficient, or 
irregular. However, further application on different buildings is required to tune the output of the framework and comparisons. Furthermore, the framework at this stage lacks validation tools to test building energy performance compared to thermal comfort measures of building occupants, or the needs and budgets of facility managers. Such validation can help prioritize the maintenance items and maximize the benefits of any maintenance action.

Future work should focus on expanding the framework presented here by incorporating the effects of occupants. In addition, algorithms should be developed for using energy performance comparisons to detect faults and problems in buildings automatically.

\section{ACKNOWLEDGEMENTS}

The authors would like to thank Robert Currie, Dean McCormick, and Wendy Kisch from Iowa State University Facilities Planning and Maintenance for their continuous support, and for sharing their expertise and experience during this project. The authors would also like to thank Kyle Younkin of ISU for his help with 3D modelling the King Pavilion building.

\section{REFERENCES}

Akcamete A. (2011). A formal approach for managing facility change information and capturing change history as part of building information models (BIMs), Carnegie Mellon University, Pittsburgh, PA, USA.

Al-Shalabi F. and Turkan Y. (2015). A novel framework for BIM enabled facility energy management: a concept paper, Proceedings of the International Construction Specialty Conference (ICSC 15), Vancouver, BC, Canada.

Andriamamonjy A., Saelens D., Klein R. (2019). A combined scientometric and conventional literature review to grasp the entire BIM knowledge and its integration with energy simulation, Journal of Building Engineering, Vol. 22, 513-527.

Arayici Y., Coates P., Koskela L., Kagioglou M., Usher C., and O'Reilly K. (2011). BIM adoption and implementation for architectural practices, Structural Survey, Vol. 29, No. 1, 7-25.

Attia S. (2010). Building performance simulation tools: selection criteria and user survey, Architecture et climat, Université catholique de Louvain, Louvain La Neuve, Belgium.

Azhar S. (2011). Building information modeling (BIM): Trends, benefits, risks, and challenges for the AEC industry, Leadership and Management in Engineering, Vol. 11, No. 3, 241-252.

Bazjanac V. (2008). IFC BIM-based methodology for semi-automated building energy performance simulation (No. LBNL-919E), Lawrence Berkeley National Laboratory, Berkeley, CA, USA.

Becerik-Gerber B., Jazizadeh F., Li N., and Calis G. (2011). Application areas and data requirements for BIMenabled facilities management, Journal of construction engineering and management, Vol. 138, No. 3 , 431-442.

Beltran A., Erickson V.L., and Cerpa A.E. (2013). Thermosense: Occupancy thermal based sensing for hvac control, Proceedings of the 5th ACM Workshop on Embedded Systems for Energy-Efficient Buildings, 18 .

Bush D. V. and Maestas J.L. (2002). Effective load management planning-A case study, Energy engineering, Vol. 99, No. 3, 71-79.

Chen D. and Gao Z. (2011). A multi-objective generic algorithm approach for optimization of building energy performance, Proceedings of the Computing in Civil Engineering Conference, 51-58.

Chen H., Hou C., and Wang Y. (2013). A 3D visualized expert system for maintenance and management of existing building facilities using reliability-based method, Expert Systems with Applications Vol. 40, No. 1, 287-299.

Cho Y. K., Alaskar S., and Bode T.A. (2010). BIM-integrated sustainable material and renewable energy simulation, Proceedings of the Construction Research Congress, 288 - 297. 
Crawley D. B., Hand J.W., Kummert M., and Griffith B.T. (2008). Contrasting the capabilities of building energy performance simulation programs, Building and environment, Vol. 43, No. 4, 661-673.

Dong B., O'Neill Z., and Li Z. (2014). A BIM-enabled information infrastructure for building energy Fault Detection and Diagnostics, Automation in Construction, Vol. 44, 197-211.

Doty, S and Turner W. C. (2013). Energy management handbook, The Fairmont Press, Inc.

Eastman C., Teicholz P., Sacks R., and Liston K. (2011). BIM handbook: A guide to building information modeling for owners, managers, designers, engineers and contractors, John Wiley \& Sons.

Kristine K. F., and Palmer M.E. (2007). General Buildings Information Handover Guide: Principles, Methodology and Case Studies, An Industry Sector Guide of the Information Handover Guide Series, NISTIR 7417.

Farzaneh A., Monfet D., Forgues D. (2019). Review of using Building Information Modeling for building energy modeling during the design process, Journal of Building Engineering, Vol. 23, 127-135.

Flores-Colen I. and Brito J. (2010). A systematic approach for maintenance budgeting of buildings façades based on predictive and preventive strategies, Construction and Building Materials, Vol. 24, No. 9, 1718-1729.

Griffith B, Pless S., Talbert B., Deru M., and Torcellini P. (2003). Energy design analysis and evaluation of a proposed air rescue and fire fighting administration building for teterboro airport, National Renewable Energy Laboratory (NREL), Golden, CO, USA.

Heiple S. and Sailor D.J. (2008). Using building energy simulation and geospatial modeling techniques to determine high resolution building sector energy consumption profiles, Energy and Buildings, Vol. 40, No. 8, pp. 1426-1436.

Hermans M.H. (1995). Deterioration characteristics of building components: a data collecting model to support performance management, Doctor of Philosophy, Department of the Built Environment, Eindhoven University of Technology.

Hong T., Chen Y., Luo X., Luo N., Lee S.H. (2020). Ten questions on urban building energy modeling, Building and environment, Vol. 168, 106508.

International Energy Agency (2008). Key world energy statistics, Technical report, Paris, France.

International Facility Management Association (IFMA) (2013). What is Facility Management.

Im P., Joe J., Bae Y., and New J. (2020). Empirical validation of building energy modeling for multi-zones commercial buildings in cooling season, Applied Energy, Vol. 261, 114374.

Jensen P.A. and Tu K.J. (2015). Establishing the DEA energy management system for individual departments within universities, Facilities, Vol. 33, No. 11/12, 716-735.

Jiang Y., Ming J., Wu D., Yen J., Mitra P., Messner J.I., and Leicht R. (2012). BIM server requirements to support the energy efficient building lifecycle, Proceedings of ASCE International Conference on Computing in Civil Engineering, 365-372.

Kamel E. and Memari A.M. (2019). Review of BIM's application in energy simulation: Tools, issues, and solutions, Automation in Construction, Vol. 97, 164-180.

Katranuschkov P., Scherer R., Weise M., and Liebich T. (2014). Extending BIM for energy simulation and design tasks, Proceedings of ASCE Computing in Civil and Building Engineering, pp. 625-632.

Kelly G., Serginson M., Lockley S., Dawood N., Kassem M. (2013). BIM for Facility management: a review and a case study investigating the value and challenges, Proceedings of 13th International Conference on Construction Applications of Virtual Reality, London, UK.

Kim A., Sunitiyoso Y., Medal L. A. (2019). Understanding facility management decision making for energy efficiency efforts for buildings at a higher education institution, Energy and Buildings, Vol. 199, No. 15, 197-215. 
Kim H., Shen Z., Kim I., Kim K., Stumpf A., and Yu J. (2016). BIM IFC information mapping to building energy analysis (BEA) model with manually extended material information, Automation in Construction, Vol. 68, 183-193.

Kim, K., Kim G., Yoo D., and Yu J. (2013). Semantic material name matching system for building energy analysis, Automation in Construction, Vol. 30, 242-255.

Lee S. and Akin O. (2011). Augmented reality-based computational fieldwork support for equipment operations and maintenance, Automation in Construction, Vol. 20, No. 4, 338-352.

Lin Y.C. and Su Y.C. (2013). Developing mobile-and BIM-based integrated visual facility maintenance management system, The Scientific World Journal, 124249.

Lin Y.C., Su Y.C., and Chen Y.P. (2012). Mobile 2D barcode/BIM-based facilities maintaining management system, Proceedings of Economics Development and Research, Vol. 43, 52-56.

Lucas J., Bulbul T., Thabet W., and Anumba C. (2012). Case analysis to identify information links between facility management and healthcare delivery information in a hospital setting, Journal of Architectural Engineering, Vol. 19, No. 2, 134-145.

Maile T., Fischer M., and Bazjanac V. (2007). Building energy performance simulation tools-a life-cycle and interoperable perspective, Center for Integrated Facility Engineering (CIFE) Working Paper, Vol. 107, $1-49$.

Motamedi A., Hammad A., and Asen Y. (2014). Knowledge-assisted BIM-based visual analytics for failure root cause detection in facilities management, Automation in Construction, Vol. 43, 73-83.

Motawa I. and Almarshad A. (2013). A knowledge-based BIM system for building maintenance, Automation in Construction, Vol. 29, 173-182.

Oh S.M., Kim Y.J., Park C.S., and Kim I.H. (2011). Process-driven BIM-based optimal design using integration of EnergyPlus, genetic algorithm, and pareto optimality, Proceedings of the 12th IBPSA Conference, 894901.

O’Sullivan B. and Keane M. (2005). Specification of an IFC based intelligent graphical user interface to support building energy simulation, Proceedings of the Ninth International Building Performance Simulation Association Conference, 15-18.

Palmer D. (1999). Maintenance planning and scheduling handbook, McGraw-Hill Professional Publishing, New York City, NY, USA.

Qin J. and Wang S. (2005). A fault detection and diagnosis strategy of VAV air-conditioning systems for improved energy and control performances, Energy and Buildings, Vol. 37, No. 10, 1035-1048.

Raheem A.A., Issa R.R.A., and Olbina S. (2011). Environmental performance analysis of a single-family house using BIM, Proceedings of ASCE International Workshop on Computing in Civil Engineering, 842-849.

Reeves T.J., Olbina S., and Issa R.R.A. (2012). Guidelines for using building information modeling (BIM) for environmental analysis of high-performance buildings, Proceedings of ASCE International Conference on Computing in Civil Engineering, 277-284.

Riley M. and Cotgrave A. (2005). Construction technology: the technology of refurbishment and maintenance Palgrave Macmillan, 3:50-6.

Roper K. and Payant R. (2014). The Facility Management Handbook, 4th Edition, American Management Association (AMACOM), New York City, NY, USA.

Roth K., Llana P., Westphalen D., and Brodrick J. (2005). Automated whole building diagnostics, ASHRAE journal, Vol. 47, No. 5, 82-84.

Sallans B., Bruckner D., and Russ G. (2006). Statistical detection of alarm conditions in building automation systems, Proceedings of the 4th IEEE International Conference on Industrial Informatics, 257-262. 
Schein J., Bushby S.T., Castro N.S., and House J.M. (2006). A rule-based fault detection method for air handling units, Energy and Buildings, Vol. 38, No. 12, 1485-1492.

Shalabi F. and Turkan Y. (2016). IFC BIM-Based Facility Management Approach to Optimize Data Collection for Corrective Maintenance, Journal of Performance of Constructed Facilities, Vol. 31, No.1, 04016081.

Song K., Ahn Y., Ahn J., and Kwon N. (2019). Development of an Energy Saving Strategy Model for Retrofitting Existing Buildings: A Korean Case Study, Energies, Vol. 12, No. 9, 1626.

Teraoka H., Bharathan B., Zhang R., Nwokafor A., Narayanaswamy B., and Agarwal Y. (2014). BuildingSherlock: Fault Management Framework for HVAC Systems in Commercial Buildings. Technical Report, Synergy Labs, Department of Computer Science and Engineering, University of California, San Diego.

Trimble Navigation Limited (2013). User Guide for Trimble TX5 3D Laser Scanner, Sunnyvale, CA, USA.

U.S. Department of Energy (2011). Buildings Energy Data Book, Energy Efficiency and Renewable Energy Department.

Volk R., Stengel J., and Schultmann F. (2014). Building Information Modeling (BIM) for existing buildingsLiterature review and future needs, Automation in Construction, Vol. 38, 109 -127.

Wang S. and Fu X. (2006). Sensor fault detection and diagnosis of air-handling units using a condition-based adaptive statistical method, HVAC\&R Research, Vol. 12, No. 1, 127-150.

Xiao F. (2004). Sensor fault detection and diagnosis of air handling units, Doctor of Philosophy, Department of Building Services Engineering, The Hong Kong Polytechnic University.

Xu X., Culligan P.J., and Taylor J.E. (2014). Energy saving alignment strategy: achieving energy efficiency in urban buildings by matching occupant temperature preferences with a building's indoor thermal environment, Applied Energy, Vol. 123, 209-219.

Yang X. and Ergan S. (2015). Leveraging BIM to Provide Automated Support for Efficient Troubleshooting of HVAC-Related Problems, Journal of Computing in Civil Engineering, Vol. 30, No. 2, 04015023.

Zhu Y. (2006). Applying computer-based simulation to energy auditing: A case study, Energy and buildings, Vol. 38, No. 5, 421-428. 